\title{
The evolution of predictive models and tourism
}

\author{
Najmeh Gharibi
}

\begin{abstract}
Purpose - This study aims to investigate the predictive technology acceptance models and their evolution in the tourism context. These predictive models make a knowledgeable decision about the possibility of future outcomes by analysing data. As futurists are interested in making a prediction about the likelihood of different behaviours over time, researchers of these predictive models have focussed on behaviour and predicting the intentions of users. This study proposes to demonstrate the revolution of these models and how are changed overtime. It also indicates the role of them in future studies.
\end{abstract}

Design/methodology/approach - By reviewing the predictive models and literature, this study looks indepth in the process of alteration of these models.

Findings - This study explores the reasons of the evolution of predictive models and how they are changed. It shed light on the role of predictive models in future research and will suggest new directions for forthcoming studies.

Research limitations/implications - One of the main limitations of this study is that as the world is currently struggling with COVID-19 and predictability of these models will be changed. As the future is disruptive, it cannot be concluded that how these models will be altered in future.

Practical implications - Role of predictive behavioural models of tourists is fundamentally crucial in assessing the performance of planners and marketers of tourism services in the future. It will also vastly helps the successful development of tourism sectors, and it has practical value for all tourism stakeholders.

Originality/value - Few studies have focussed on the evaluation of these models and their role in future research.

Keywords Behaviour, Future, Tourism, Technology Acceptance, Intentions, Predictive models

Paper type Trends paper

\section{Literature review}

\section{Evolution of predictive models}

After people's overreliance on technology in their daily lives, researchers and marketers have tried to predict the usage behaviour and intention of using technology. They have examined various theories to explore the reasons for individuals' accepting or refusing a new technology, a field which turned into one of the fundamental areas of research (Momani et al., 2018). These models help researchers to provide predictions on intentional behaviour and show why a special technology may be accepted or abandoned by users (Rapp et al., 2019). Taherdoost (2018) has stated that these models are developed over the years to forecast the acceptance of technology by individuals and their ability to adopt new technologies.

From the 1970s, research on technology acceptance has developed notably because of the increasing interest of researchers to investigate the fundamental factors behind the users' adoption of the new technologies. The earliest theory of technology acceptance is the theory of reasoned action (TRA), which was developed by Ajzen and Fishbein in 1967 including factors of attitudes, social norms and intentions (Nguyen et al., 2018).
Najmeh Gharibi is based at the Department of Tourism Management, Victoria University of Wellington, Wellington, New Zealand.

Received 1 April 2020 Revised 14 June 2020 Accepted 14 June 2020

(C) Najmeh Gharibi. Published in Journal of Tourism Futures. Published by Emerald Publishing Limited. This article is published under the Creative Commons Attribution (CC BY 4.0) license. Anyone may reproduce, distribute, translate and create derivative works of this article (for both commercial and non-commercial purposes), subject to full attribution to the original publication and authors. The full terms of this license may be seen at http://creativecommons.org/licences/by/4.0/ legalcode 
In the 1980s, the theory of planned behaviour (TPB) was proposed by Ajzen (1985) which became popular at that time. In this theory, perceived behavioural control as a new variable was added to the TRA model to improve on the predictive power of the TRA.

It was in the late 1980s that the technology acceptance model (TAM) was created drawing upon the TRA model, proposed by Davis in 1989. As it included most of the factors regarding users' intentional behaviour, the TAM became one of the most popular models in predicting information technology adoption at that time (Wu, 2009). This model explains that users will be motivated by three factors, namely, perceived usefulness, perceived ease of use and attitude towards use.

Since the TAM was proposed in 1989, most of the scholars have tried to predict behaviour by using the TAM in several ways. Many researchers have tried to add external variables to the original one (Jung, 2019) to predict behaviour. Some other expanded the original TAM and proposed new predictive models (TAM 2 by Venkatesh and Davis, 2000; unified theory of acceptance and use of technology [UTAUT] by Venkatesh et al., 2003; UTAUT 2 by Viswanath et al., 2012; UTAUT 3 by Al sahouly, 2015). Furthermore, some researchers have combined two theories to predict the intentional behaviour of users towards technologies (Safeena et al., 2013).

In the tourism context, a lot of research has been conducted to predict tourists' technology acceptance. Reviewing 71 articles of predictive models in the tourism field, Ukpabi and Karjaluoto (2017) found that the TAM was the most commonly used model (33\% of the studies) in these studies. The TBP was applied in $14 \%$ of studies, $7 \%$ of the studies used the UTAU and the TRA was used by $5 \%$. Other studies combined these models to investigate the determinants of tourist's acceptance of technologies. These modified theories aimed to predict tourists behaviour in historical visitors' attractions (Lagiewski and Kesgin, 2017), wine tourism (Martins et al., 2017) and urban heritage tourism (tom Dieck and Jung, 2018). Review of all predictive models and theories shows two key significance in the development stages of these models which has been mainly based on the changeability of behaviour and revolution of technologies.

Anticipating how a particular emerging technology might change, is regarded as the competitive issue of any industry (Christensen, 2013) and the future of a new technology can be hard to predict with certainty (Krotov, 2019). The revolution of technologies has slightly changed the focus of tourists from websites to smartphones, and now to sensors and portable devices as they play a fundamental part in all steps of their trip (Buhalis and Amaranggana, 2015). In the tourism industry, services has alerted from inactive consumption to a more engaging one by appearance of new technologies (Taheri et al., 2019).

However, one of the limitations of predictive models is that they need to be fastly renovated as technology develops much faster than the transformation of these predictive models. For instance, it is not clear if the realities such as augmented reality (AR) are capable of improving customers behaviour (Raska and Richter, 2017) or the literature on the adoption of extended reality (XR) technologies is scarce (Moorhouse et al., 2018). Additionally, some others emphasised that there is a need to develop a particular framework for virtual reality (VR) and AR technology for analysing tourists' behaviour and their intention to use these technologies or refuse to apply them (Loureiro et al., 2020). In spite of the vast growth of XR, consumer acceptance is still limited and academic research on such technology and their applications are extremely restricted (Bonetti et al., 2018). For instance, companies and researchers who are studying the use of wearable devices in tourism (Chuah, 2019), demonstrated that little attention has been paid to using predictive models for XR wearable technology acceptance which is a new technology (Herz and Rauschnabel, 2019).

Another weakness of predictive models is that some researchers have highlighted an absence of a theory in the literature that covers the technology post-acceptance stage (Ghapanchi and Talaei-Khoei, 2018) because many of these studies focussed exclusively on the acceptance phase (Dwivedi et al., 2019). From the 1970s, several kinds of technology acceptance models and theories have been developed by researchers to predict users' behaviour in the tourism context. However, less research is performed 
regarding the use and the continued use of technology (Ismail et al., 2018). Therefore, these predictive models should focus on practical usage of technologies rather than just acceptance phase which it is not clear if the users ultimately use that technology (Ghapanchi and Talaei-Khoei, 2018). Continuous use is different from acceptance as in this stage the user previously has accepted the technology and is already familiar with it (Ismail et al., 2018). It is also known as post-acceptance of technology. There are only a few models available currently in IS literature that have investigated the subjects adjoining the actual use or continued use of technology (Roy et al., 2017).

Röcker (2010) has explained that some factors of TAM as a popular predictive model such as ease-of-use that were used to anticipate technology adoption for years, might not be proper anymore. They also stated that some new factors, that have not been included in any of the existing models, could play important roles in predicting behaviour and these models are needed to be changed. Pourfakhimi et al. (2018), also suggest that after three decades of repeated use of a few classical predictive models, the future models need to focus on taking more novel approaches to explore the essential factors behind the acceptance of tourism technologies to extend our understanding of tourism technology acceptance,

The second key element of the development of the prective models has been related to behavioural change. The behaviour of tourists is the most fundamental predictor of future tourist behaviour (Juvan et al., 2017). As Saeed (2019) emphasised, predicting behaviour is a challenging issue, as behaviour changes over time. A customer may be pleased today but not loyal in the future. Predictive models are changing as individuals may change their behaviour in different ways over time and based on the prediction of a future event. Therefore, this leads to changing the structure of these predictive models based on behavioural dynamism and their influential factors (Goulias, 2016). Juvan et al. (2017) argue that tourist's behaviour is related to different forms of behaviour in each stage of traveling, the process of monitoring tourist behaviour is complicated which is why there are many adaption models that may be useless for making business decisions. Finally, tourist behaviour has dramatically changed with the advent of modern communication tools during the time (Caldito et al., 2015). Therefore, transformation of both technology and behaviour occurs over time. It means that these models have to be changed to improve their predictability. Very recently, Loureiro et al. (2020) have reviewed 20 years of research on VR and AR in tourism, confirming that the TAM has been one of the most proper theories in the context of virtual tourism. Nevertheless, researchers emphasised that developments of new technologies would lead to alteration in the behaviour of tourists and their decision-making processes (Wang et al., 2013).

It should be noted that most of the existing predictive models have not investigated on how emotions are related to technology acceptance. Some scholars underline that although the enrichment of experience has been widely investigated, limited research has been accomplished to explore technology-emotion relationship on experience enhancement (Zhang et al., 2018). This is the area which can be considered in future predictive models.

Another issue is that previous studies on predictive models have not focussed on dark side of technology accpetance and less is known about why users resist to technology which is a major reason for the failures of new IS implementation (Chuah, 2019). For instance, Suh and Prophet (2018), have highlighted the negative parts of technology acceptance models such as motion sickness, physical discomfort, cognitive overload and distracted attrition, which could increase user stress levels.

Finally, with current disruption of COVID-19 all over the world which causes the most severe disruption of the global economy since Second World War (Gössling et al., 2020) presence of technology is abruptly soaring in our lives. Researchers highlight that the year of 2020 is tend to be the beginning of an exciting decade with the development and maturation of several digital technologies (Ting et al., 2020). So the role of technology in human's life has significantly transformed over the past few months and will continue to change. This will make a disruptive 
future towards the direction of researchers in predicting behaviours and intention. So, with this rapid and abrupt usage of technology over the past months by human, the future of predictive models will be revolutionized and will be more unpredictable in any area including tourism.

Therefore, based on the review of predictive models, it is argued that direction of the revolution of these models will be affected by various factors which has been shown in Figure 1.

\section{The role of prediction models in future research}

Change is always considered as a crucial part of future studies as researchers are continuously confronting with alterations. Future research tends to predict upcoming possibilities as accurately as achievable, based on their knowledge about the past. The majority of future researchers will likely consider that the future is predictable (Mannermaa, 1991). However, futurists always argue about predicting the possible futures, (Bergman et al., 2010) as there has been a modification from making a precise prediction to several conclusions (Strand, 1999).

Predicting the behaviour of tourists is considered as one of the most influential factors in assessing the performance of planners and providers of tourism in the future. It will also shed light on the successful development of tourism sectors, and it has practical value for all tourism stakeholders (Juvan et al., 2017). Researchers, who are interested on finding the direction of predictive models, make a precise prediction or scenario planning, which includes several outcomes. These predictive models anticipate various theories to investigate individuals' acceptance or refusal of a new technology. Researchers have found that these behavioural models are valuable, as they focus on perceptible variables that are involved by technology, indicating practical challenges and opportunities for measurable results (Rapp et al., 2019). Van Vuuren and Slabbert (2012) also highlight that the prediction of travel behaviour by these predictive models play a crucial role in tourism marketing as they will make tourism marketers able to help tourists in decision-making.

\section{Conclusion}

This study reviewed the revolution of predictive models in tourism and explored the gaps and limitations of these models. It also proposed a new transformational direction of these models for future research.

\section{Figure 1 Future of predictive models}

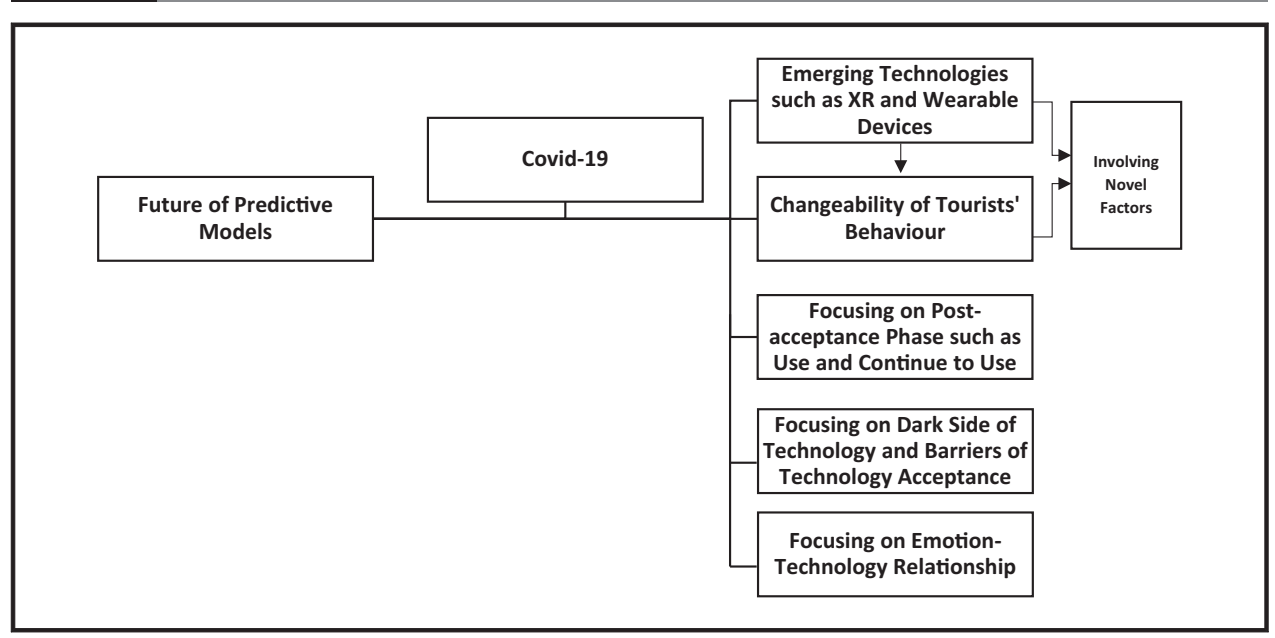


Based on the literature, it has been indicated that since the development of predictive models in the 1970s, researchers on technology acceptance have been adding various external variables to the existing models. Three decades after the development of TAM factors researchers are firmly agreed that the impact of these factors on technology acceptance is insignificant. Future research should into consideration that investigating some factors of these models, such as perceived usefulness, do not seem to expand our knowledge on tourists' technology acceptance. Accordingly, innovative factors and novel frameworks may be helpful in predicting the behaviour. Future predictive models need to be concerned about the changeability of tourists' behaviour. Affective and hedonic factors such as flow (Gao and Bai, 2014) and existing technology-related dispositions (Ponte et al., 2015) are examples of factors that definitely will expand the predictability of tourism technology acceptance models.

As tourists are already familiar and have adopted to various technologies, these models can focus more on post-acceptance phase such as use and continue to use of technology. They also should pay attention to on emotion-technology relationship. Besides, future predictive models are supposed to consider the dark side of technology and barriers of technology acceptance such as distracted attrition.

Moreover, it should be pointed out that because of the changeability of technology and alterations in tourists' behaviour and intentions, future research should focus on developing new theories and frameworks to provide multiple outcomes for tourists' behaviour. Furthermore, it can be concluded that research on new technologies such as wearable devices acceptance, compared to computers and smartphones, is still rare, and users' behaviour regarding various technological devices is different from each other. For instance, the acceptance of extended realities (VR, AR and MR) in the tourism context and predicting behaviour of tourists towards using them is still at the preliminary stage.

Finally, it can be concluded that all these years of revolution and change in predictive models have been based on regular behavioural modifications, which shows that an individual's behaviour towards technology changes gradually. However, today world is facing an abrupt revolution in relation of using technologies due to COVID-19 situation. Indeed, it has been a long time that human has found that technology is a necessity; however, until now; no incident has made this fact clearer than the global coronavirus pandemic. For the first time in history, businesses and individuals have to stay inside and continue their job, relying on technology, a situation which changed many businesses completely. This disruption makes the future unknown to researchers as this transformational change brings various scenarios to the prediction of behaviours. This massive amount of using technology and how it will change our life makes it so challenging for researchers to predict the behaviour of users. Future research needs to keep being updated while understanding the world situation and seeing the bigger picture.

\section{References}

Ajzen, I. (1985), "From intentions to actions: a theory of planned behavior", in Action Control, Springer, pp. 11-39.

Al-Sahouly, I. (2015), "Investigating the factors affecting business-to-consumer e-commerce adoption in Egypt", University of Salford.

Bergman, A., Karlsson, J.C. and Axelsson, J. (2010), "Truth claims and explanatory claims - an ontological typology of futures studies”, Futures, Vol. 42 No. 8, pp. 857-865.

Bonetti, F., Warnaby, G. and Quinn, L. (2018), "Augmented reality and virtual reality in physical and online retailing: a review, synthesis and research agenda", in Augmented Reality and Virtual Reality, Springer, pp. 119-132. 
Buhalis, D. and Amaranggana, A. (2015), "Smart tourism destinations enhancing tourism experience through personalisation of services", in Information and Communication Technologies in Tourism 2015, Springer, pp. 377-389.

Caldito, L.A., Dimanche, F. and Ilkevich, S. (2015), "Tourist behaviour and trends", Tourism in Russia: A Management Handbook, Emerald Group Publishing Limited, Bingley, West Yorkshire, pp. 101-130.

Christensen, C.M. (2013), The Innovator's Dilemma: When New Technologies Cause Great Firms to Fail, Harvard Business Review Press.

Chuah, S.H.W. (2019), "Wearable XR-technology: literature review, conceptual framework and future research directions", International Journal of Technology Marketing, Vol. 13 Nos 3/4, pp. 205-259.

Dwivedi, Y.K., Rana, N.P., Jeyaraj, A., Clement, M. and Williams, M.D. (2019), "Re-examining the unified theory of acceptance and use of technology (UTAUT): towards a revised theoretical model", Information Systems Frontiers, Vol. 21 No. 3, pp. 719-734.

Gao, L. and Bai, X. (2014), "Online consumer behaviour and its relationship to website atmospheric induced flow: insights into online travel agencies in China", Journal of Retailing and Consumer Services, Vol. 21 No. 4, pp. 653-665.

Ghapanchi, A.H. and Talaei-Khoei, A. (2018), "Rethinking technology acceptance: towards a theory of technology utilization".

Gössling, S., Scott, D. and Hall, C.M. (2020), "Pandemics, tourism and global change: a rapid assessment of COVID-19", Journal of Sustainable Tourism, pp. 1-20.

Goulias, K.G. (2016), "Travel behavior models", in Draft of a Chapter for Handbook of Behavioral and Cognitive Geography (ed. Montello).

Herz, M. and Rauschnabel, P.A. (2019), "Understanding the diffusion of virtual reality glasses: the role of media, fashion and technology", Technological Forecasting and Social Change, Vol. 138, pp. 228-242.

Ismail, N., Hasan, M.H. and Mustapha, E. (2018), "Technology use, emotional connection and their relationship: a literature review", Journal of Theoretical and Applied Information Technology, Vol. 96 No. 1, pp. 127-139.

Jung, D. (2019), "Assessing citizen adoption of e-government initiatives in Gambia: a validation of the technology acceptance model in information systems success". A critical article review, with questions to its publishers, Government Information Quarterly, Vol. 36 No. 1, pp. 5-7.

Juvan, E., Gomezeli Omerzel, D. and Uran Maravic, M. (2017), "Tourist behaviour: an overview of models to date", Paper presented at the Management International Conference.

Krotov, V. (2019), "Predicting the future of disruptive technologies: the method of alternative histories", Business Horizons, Vol. 62 No. 6, pp. 695-705.

Lagiewski, R. and Kesgin, M. (2017), "Designing and implementing digital visitor experiences in New York state: the case of the finger Lakes interactive play (FLIP) project", Journal of Destination Marketing \& Management, Vol. 6 No. 2, pp. 118-126.

Loureiro, S.M.C., Guerreiro, J. and Ali, F. (2020), "20 Years of research on virtual reality and augmented reality in tourism context: a text-mining approach", Tourism Management, Vol. 77, p. 104028.

Mannermaa, M. (1991), "In search of an evolutionary paradigm for futures research", Futures, Vol. 23 No. 4, pp. 349-372.

Martins, J., Gonçalves, R., Branco, F., Barbosa, L., Melo, M. and Bessa, M. (2017), "A multisensory virtual experience model for thematic tourism: a port wine tourism application proposal", Journal of Destination Marketing \& Management, Vol. 6 No. 2, pp. 103-109.

Momani, A.M., Jamous, M.M. and Hilles, S.M. (2018), "Technology acceptance theories: review and classification", in Technology Adoption and Social Issues: Concepts, Methodologies, Tools and Applications, IGI Global, pp. 1-16.

Moorhouse, N., Tom Dieck, M.C. and Jung, T. (2018), "Technological innovations transforming the consumer retail experience: a review of literature", in Augmented Reality and Virtual Reality, Springer, pp. 133-143. 
Nguyen, Q.A., Hens, L., MacAlister, C., Johnson, L., Lebel, B., Bach Tan, S., Lebel, L. (2018), "Theory of reasoned action as a framework for communicating climate risk: a case study of schoolchildren in the Mekong Delta in Vietnam", Sustainability, Vol. 10 No. 6, p. 2019.

Ponte, E.B., Carvajal-Trujillo, E. and Escobar-Rodríguez, T. (2015), "Influence of trust and perceived value on the intention to purchase travel online: integrating the effects of assurance on trust antecedents", Tourism Management, Vol. 47, pp. 286-302.

Pourfakhimi, S., Duncan, T. and Coetzee, W. (2018), "A synthesis of technology acceptance research in tourism \& hospitality", In Information and Communication Technologies in Tourism 2018, Springer, pp. 143-155.

Rapp, A., Tirassa, M. and Tirabeni, L. (2019), "Rethinking technologies for behavior change: a view from the inside of human change", ACM Transactions on Computer-Human Interaction, Vol. 26 No. 4, pp. 1-30.

Raska, K. and Richter, T. (2017), "Influence of augmented reality on purchase intention: the IKEA case".

Röcker, C. (2010), "Why traditional technology acceptance models won't work for future information technologies", World Academy of Science, Engineering and Technology, Vol. 65, pp. 237-243.

Roy, S., Ponnam, A. and Mandal, S. (2017), "Comprehending technology attachment in the case of smart phone-applications: an empirical study", Journal of Electronic Commerce in Organizations, Vol. 15 No. 1, pp. 23-43.

Saeed, Z. (2019), "A study of theories on consumer behavior", Journal of Computing and Management Studies, Vol. 3 No. 1.

Safeena, R., Date, H., Hundewale, N. and Kammani, A. (2013), "Combination of TAM and TPB in internet banking adoption”, International Journal of Computer Theory and Engineering, Vol. 5 No. 1, p. 146.

Strand, S. (1999), "Forecasting the future: pitfalls in controlling for uncertainty", Futures, Vol. 31 Nos 3/4, pp. 333-350.

Suh, A. and Prophet, J. (2018), "The state of immersive technology research: a literature analysis", Computers in Human Behavior, Vol. 86, pp. 77-90.

Taherdoost, H. (2018), "A review of technology acceptance and adoption models and theories", Procedia Manufacturing, Vol. 22, pp. 960-967.

Taheri, B., Hosany, S. and Altinay, L. (2019), Consumer Engagement in the Tourism Industry: new Trends and Implications for Research, Taylor \& Francis.

Ting, D.S.W., Carin, L., Dzau, V. and Wong, T.Y. (2020), "Digital technology and COVID-19", Nature Medicine, Vol. 26 No. 4, pp. 459-461.

Tom Dieck, M.C. and Jung, T. (2018), "A theoretical model of mobile augmented reality acceptance in urban heritage tourism", Current Issues in Tourism, Vol. 21 No. 2, pp. 154-174.

Ukpabi, D.C. and Karjaluoto, H. (2017), "Consumers' acceptance of information and communications technology in tourism: a review", Telematics and Informatics, Vol. 34 No. 5, pp. 618-644.

Van Vuuren, C. and Slabbert, E. (2012), "Travel motivations and behaviour of tourists to a South African resort", Tourism \& Management Studies, pp. 295-304.

Venkatesh, V., Thong, J.Y. and Xu, X. (2012), "Consumer acceptance and use of information technology: extending the unified theory of acceptance and use of technology", MIS quarterly, pp. 157-178.

Venkatesh, V., Morris, M.G., Davis, G.B. and Davis, F.D. (2003), "User acceptance of information technology: Toward a unified view", MIS quarterly, pp. 425-478.

Venkatesh, V. and Davis, F.D. (2000), "A theoretical extension of the technology acceptance model: Four longitudinal field studies", Management science, Vol. 46 No. 2, pp. 186-206.

Wang, X., Kim, M.J., Love, P.E. and Kang, S.-C. (2013), "Augmented reality in built environment: classification and implications for future research", Automation in Construction, Vol. 32, pp. 1-13.

Wu, P.F. (2009), "User acceptance of emergency alert technology: a case study", Paper presented at the Proceedings of the 6th International ISCRAM Conference. 
Zhang, H., Gordon, S., Buhalis, D. and Ding, X. (2018), "Experience value cocreation on destination online platforms", Journal of Travel Research, Vol. 57 No. 8, pp. 1093-1107.

\section{About the author}

Najmeh Gharibi is currently studying PhD in Tourism Management at Victoria University of Wellington. Naji has several research publications and conference papers and has got a master's degree in Tourism Management. She is interested in Tourism and Technology, Future of Tourism and Tourists' Behaviour. Najmeh Gharibi can be contacted at: naji. gharibi@vuw.ac.nz

For instructions on how to order reprints of this article, please visit our website: www.emeraldgrouppublishing.com/licensing/reprints.htm

Or contact us for further details: permissions@emeraldinsight.com 